\title{
Farklı inkübasyon dönemlerinde uygulanan vermikompostun marul bitkisinin bitki besin element içeriği üzerine etkileri
}

\section{The effects of vermicompost application on the nutrient elements contents of lettuce plant during different incubation periods}

\author{
Nil ÖZEN ${ }^{1}$ (i), Sahriye SÖNMEZ ${ }^{2}$ (D) \\ ${ }^{1}$ Akdeniz Üniversitesi, Fen Bilimleri Enst., Toprak Bilimi ve Bitki Besleme ABD, Antalya \\ ${ }^{2}$ Akdeniz Üniversitesi, Ziraat Fakültesi, Toprak Bilimi ve Bitki Besleme Bölümü, Antalya \\ Sorumlu yazar (Corresponding author): S. Sönmez, e-posta (e-mail): ssonmez@akdeniz.edu.tr \\ Yazar(lar) e-posta (Author e-mail): nilozen@ hotmail.com
}

\section{MAKALE BİLGİSİ}

Alınış tarihi 12 Mart 2019

Düzeltilme tarihi 19 Nisan 2019

Kabul tarihi 26 Nisan 2019

\section{Anahtar Kelimeler:}

Bitki besin maddesi

İnkübasyon

Marul

Vermikompost

\begin{abstract}
ÖZ
Bu çalışmada, farklı mineralizasyon oranına sahip vermikompost uygulamalarının, marul bitkisinin bitki besin element içeriği üzerine etkilerinin araştırılması amaçlanmıştır. Bu amaçla; vermikompost 4 dozda $\left(0,50,100\right.$ ve $\left.200 \mathrm{~kg} \mathrm{da}^{-1}\right)$ uygulanmış, 0,30 ve 60 gün inkübasyona bırakıılmıștır. Serada yürütülen bu çalışma, tesadüf blokları deneme desenine göre 3 tekerrürlü olarak yürütülmüsş ve deneme bitkisi olarak Yedikule düz marul çeşidi kullanılmıştır. Denemede, bütün marul fidelerinin aynı günde dikilebilmesi amacıyla ilk önce 60 . gün inkübasyona tabi tutulan uygulamalar, daha sonra toprağa 30 . ve 0 . günde uygulanan vermikompostlar toprağa karıştırılmış ve marul fideleri aynı gün saksılara dikilmiştir. 9 haftalık yetişme periyodu sonunda bitkiler hasat edilmiștir. Hasat sonrası marul bitkilerinde azot $(\mathrm{N})$, fosfor $(\mathrm{P})$, potasyum $(\mathrm{K})$, kalsiyum $(\mathrm{Ca})$, magnezyum $(\mathrm{Mg})$, demir $(\mathrm{Fe})$, mangan $(\mathrm{Mn})$, çinko $(\mathrm{Zn})$, bakır $(\mathrm{Cu})$, kükürt $(\mathrm{S})$ ve bor $(\mathrm{B})$ analizleri yapılmıştır. Vermikompost uygulamalarında, farklı inkübasyon sürelerinin marul bitkisinin $\mathrm{N}, \mathrm{P}, \mathrm{K}, \mathrm{Ca}, \mathrm{Mg}, \mathrm{S}, \mathrm{Zn}, \mathrm{Fe}, \mathrm{Mn}, \mathrm{Cu}$, B içerikleri üzerine etkileri istatistiksel olarak önemli bulunmustur. Deneme sonucunda; inkübasyon süresinin uzamasına (60. güne doğru) bağlı olarak marul bitkisinin $\mathrm{Ca}$ ve $\mathrm{Mg}$ içeriklerinin arttığı; $\mathrm{P}$, $\mathrm{Zn}$ ve B içeriklerinin ise azaldığı tespit edilmiştir. Marul bitkilerinin K, $\mathrm{S}, \mathrm{Mn}$ ve Cu içeriklerinin 30 . güne doğru azaldığı ancak 60. günde arttığı; bitkilerin $\mathrm{N}$ ve Fe içeriklerinin ise 30. güne kadar arttığ 1 ancak 60. günde azaldığı belirlenmiştir. Artan düzeyde yapılan vermikompost uygulamalarının marul bitkisinin $\mathrm{N}, \mathrm{P}, \mathrm{K}, \mathrm{Mg}, \mathrm{S}, \mathrm{Fe}, \mathrm{Mn}, \mathrm{Zn}, \mathrm{Cu}$ ve B içerikleri üzerine etkileri istatistiksel olarak önemli bulunurken; $\mathrm{Ca}$ içeriği üzerine etkisi önemsiz bulunmuștur. Artan vermikompost uygulamalarına bağlı olarak marul bitkisinin $\mathrm{N}, \mathrm{P}, \mathrm{K}, \mathrm{Mn}, \mathrm{Zn}, \mathrm{Fe}$ ve S içeriklerinin genel olarak $\operatorname{arttığı;~Mg,~Cu~ve~B~içeriklerinin~ise~azaldığı~belirlenmiştir.~}$
\end{abstract}

\section{ARTICLE INFO}

Received 12 March 2019

Received in revised form 19 April 2019

Accepted 26 April 2019

\section{Keywords:}

Plant nutrients

Incubation

Lettuce

Vermicompost

\begin{abstract}
In this study, it was aimed to investigate the effects of vermicompost application with different mineralization ratio on the nutrients contents of lettuce plant. For this, vermicompost were used at 4 doses $\left(0,50,100\right.$ and $\left.200 \mathrm{~kg} \mathrm{da}^{-1}\right)$, and left to the incubation for 0,30 and 60 days. This study was carried out in 3 replications according to randomized block trial design in greenhouse conditions and Yedikule lettuce variety was used as a trial plant. In experiment; in order to be able to plant whole lettuce seedlings on the same day, firstly vermicompost materials applied to the soil on 60 days incubations, then on the $30^{\text {th }}$ and $0^{\text {th }}$ day were mixed in the soil, and the lettuce seedlings were planted in the pots on the same day. At the end of the 9-week growing period, the plants were harvested. The harvested lettuce plants were analyzed for $\mathrm{N}, \mathrm{P}, \mathrm{Ca}, \mathrm{Mg}, \mathrm{Fe}, \mathrm{Mn}, \mathrm{Zn}, \mathrm{Cu}, \mathrm{S}$ and $\mathrm{B}$. The effects of different incubation times on the N, P, K, Ca, Mg, S, Zn, Fe, Mn, Cu, B contents of the lettuce plant were significant. As a result of the experiment; it was determined that the $\mathrm{Ca}$ and $\mathrm{Mg}$ contents increased during incubation periods, while $\mathrm{P}, \mathrm{Zn}$ and $\mathrm{B}$ contents decreased. Also, it was determined that the $\mathrm{K}, \mathrm{S}, \mathrm{Mn}$ and $\mathrm{Cu}$ contents of lettuce plants decreased to $30^{\text {th }}$ day but increased at $60^{\text {th }}$ day; the $\mathrm{N}$ and $\mathrm{Fe}$ contents of the plants increased until 30 days, but decreased at 60 days. The effects of vermicompost applications on the $\mathrm{N}, \mathrm{P}, \mathrm{K}, \mathrm{Mg}, \mathrm{S}, \mathrm{Fe}, \mathrm{Mn}, \mathrm{Zn}, \mathrm{Cu}$ and $\mathrm{B}$ contents of lettuce plants were found to be statistically significant. The effect on Ca content was insignificant. Depending on increasing vermicompost applications; it was determined that the N, P, K, Mn, Zn, Fe and $\mathrm{S}$ contents of lettuce plants increased and $\mathrm{Mg}, \mathrm{Cu}$ and $\mathrm{B}$ contents decreased.
\end{abstract}




\section{Giriş}

Marul bitkisi tek yıllık, soğuğa kısmen dayanıklı, nemli hava koşullarına gereksinim duyan, 1lıman iklim bitkisidir. Yetiştirme süresi 2-3 ay gibi kısa bir süredir. Marul bitkisi hemen hemen her toprakta yetişebildiği gibi, en iyi kumlu tın ve killi tın arasında kalan topraklarda yetişmektedir. Yüzeysel köklü olduğu için toprağın 20-30 cm'lik üst kısmının yeterli besin maddesi içermesi gerekmektedir. Marul bitkisi organik maddece zengin toprakta iyi yetişerek, kısa sürede hasat olgunluğuna erişmektedir.

Yaprağı tüketilen sebzelerde organik gübreler çok önem taşımaktadır. Çünkü yaprakta koyu yeşil renge erişebilmek için aşırı azotlu gübre yapılmaktadır. Aşırı azotlu gübrelemenin sonucunda ise taze olarak tükettiğimiz yapraklar canlı sağlığına olumsuz etkiler yaratmakta, yer altı sularımızın kirlenmesine sebep olmaktadır (Venter 1978; Fritz 1983). Tüketilen gıdalar arasında nitrat birikiminin en fazla olduğu sebzenin marul bitkisi olduğu belirtilmiştir (Santamaria 2006). Özellikle azotlu gübrelerin aşırı verilmesi halinde bitki yapraklarında biriken nitritin insan vücudunda olumsuz etki yaptığı saptanmıştır (Vural ve ark. 2000).

Artan dünya nüfusuyla birlikte gidaya ihtiyaçta doğru orantılı olarak artış göstermektedir. Böylelikle birim alandan elde edilen miktarın arttırılması hedeflenmektedir. Ancak uygulanan gübre ve kimyasal ilaçların kullanımı bir yandan verimi arttırmada etkili olurken, diğer yandan insan sağlığını olumsuz yönde etkilemekte ve aynı zamanda topraklarımızın tuzlanmasına, çoraklaşmasına, fiziksel yapının ve besin maddesi dengesinin bozulmasına neden olmaktadır.

Karşılaştı̆̆ımız çevre sorunlarından dolayı organik gübre kullanımı artış göstermiştir. Son yıllarda dünyada organik ürünlere eğilimin arttı̆̆ 1 da birçok araştırmacı tarafindan bildirilmektedir (Ngouajio ve ark. 2003).

Toprağa organik materyal ilavesiyle toprağın kendi bünyesinde bulunan organik madde miktarı artmakta, buna bağlı olarak toprağın agregat stabilitesi, hava-su dengesi, erozyona karşı direnci ve topraktaki bitki besin elementlerinin alımı olumlu yönde etkilenerek artmaktadır. Dünyanın farklı bölgelerinde yapılan araştırmalar organik materyallerin toprak özelliklerini iyileştirerek elde edilen ürünlerde verimin arttığını belirlemişlerdir (Olsen ve ark. 1970, Sommerfieldth ve Chang 1985, Kütük ve ark. 1999). Organik materyallerin tarımda kullanılması hem tarım hem de çevre koruma açısından yararlı olup çevre kirliliğini azaltmaktadır.

En yaygın kullanılan materyallerden birisi de komposttur. Kompost nispeten düşük maliyetli ticari bir organik azot ve organik madde kaynağıdır. Ayrıca düşük miktarlarda K, P, Mg, $\mathrm{Ca}, \mathrm{S}$ ve diğer mikro besin elementlerini de içermektedir. Son zamanlar da çok duyulan ve popülarite kazanan organik gübrelerden birisi de vermikomposttur. Vermikompost, organik materyallerin solucanlar kullanilarak humus benzeri materyallere dönüştürülmesi ile elde edilmektedir (Garg ve ark. 2010). Yapılan araştırmalar, toprağa vermikompost uygulamasının yetiştirilen bitkinin ihtiyaç duyduğu bitki besin maddesi içeriğini karşıladığını ve besin maddesi alınımını arttırdı̆̆ını göstermiştir (Peyvast ve ark. 2007).

Organik uygulamaların topraklardaki mineralizasyon oran üzerine inkübasyon sürelerinin oldukça önemli etkiye sahip olduğu pek çok araştırmacı tarafından ifade edilmiştir. Kara (1997), 6-7 haftalık inkübasyon sonrası toprakların mineralize olabilir $\mathrm{N}$ içeriklerinin maksimuma ulaştığını tespit etmiştir.
Kızıloğlu ve ark. (2001), inkübasyon süresi sonunda, nitrifikasyon kapasitelerinin azotlu gübrelemeden etkilendiğini ve 30. inkübasyon gününde gübre ilavesine bağlı olarak nitrifikasyon kapasitelerinin artış gösterdiğini tespit etmişlerdir.

Bu çalışmayla, farklı inkübasyon dönemlerinde uygulanmış olan vermikompostun marul bitkisinin bitki besin element $(\mathrm{N}$, $\mathrm{P}, \mathrm{K}, \mathrm{Ca}, \mathrm{Mg}, \mathrm{S}, \mathrm{Zn}, \mathrm{Fe}, \mathrm{Mn}, \mathrm{Cu}$ ve B) içerikleri üzerine olan etkilerinin belirlenmesi amaçlanmıştır.

\section{Materyal ve Yöntem}

Deneme, Akdeniz Üniversitesi Tohumculuk ve Tarımsal Biyoteknoloji Araştırma ve Uygulama Merkezi'ne ait serada yürütülmüştür. Farklı inkübasyon dönemlerinde uygulanan vermikompostun marul bitkisinin bitki besin element içeriği üzerine etkilerini belirlemek için yürütülen deneme, 4 L'lik saksılarda tesadüf blokları deneme desenine göre 3 tekerrürlü olarak gerçekleştirilmiştir. Denemede; vermikompost 4 farklı dozda $\left(0,50,100\right.$ ve $\left.200 \mathrm{~kg} \mathrm{da}^{-1}\right)$ uygulanmış ve 0,30 ve 60 gün inkübasyona bırakılmıştır. Deneme; 4 farklı uygulama dozu, 3 farklı inkübasyon süresi ve 3 tekerrürlü olmak üzere 36 saksıdan oluşmuştur. Organik materyal olarak kullanılan vermikompostun; $\mathrm{pH}$ ve EC düzeyleri 1:2.5 oranında toprak-su karışımında (Jackson 1967), toplam N içeriği Kjeldahl yöntemine göre (Kacar ve İnal 2010); P, K, Ca, Mg, Na, Fe, $\mathrm{Mn}, \mathrm{Zn}$ ve $\mathrm{Cu}$ içerikleri yaş yakma sonucu elde edilen süzükte (Kacar ve İnal 2010) ICP cihazında okunan sonuclara göre belirlenmiş ve sonuçlar Çizelge 1' de verilmiştir.

Araştırmada kullanılan toprağın bazı fiziksel ve kimyasal analiz sonuçları Çizelge 2'de verilmiştir. Denemede kullanılan toprağın toplam $\mathrm{N}$ içeriği Kjeldahl yöntemine göre (Kacar 2014), alınabilir P içeriği Olsen yöntemine göre (Olsen ve Dean, 1965), değişebilir $\mathrm{K}, \mathrm{Ca}, \mathrm{Mg}$ içerikleri $1 \mathrm{~N}$ amonyum asetat ( $\mathrm{pH} 7$ ) metoduna göre (Kacar 2014), ekstrakte edilebilir $\mathrm{Fe}, \mathrm{Zn}, \mathrm{Cu}, \mathrm{Mn}$ içerikleri DTPA metoduna göre (Lindsay ve Norvell 1978) belirlenmiştir.

Çizelge 1. Vermikompostun kimyasal özellikleri.

Table 1. Chemical properties of vermicompost.

\begin{tabular}{lclc}
\hline Parametreler & Sonuçlar & Parametreler & Sonuçlar \\
\hline $\mathrm{pH}$ & 7.46 & $\mathrm{Ca}, \mathrm{ppm}$ & 5378 \\
$\mathrm{EC}, \mathrm{dS} \mathrm{m}^{-1}$ & 6.53 & $\mathrm{Mg}, \mathrm{ppm}$ & 1193 \\
Toplam N, \% & 1.103 & $\mathrm{Mn}, \mathrm{ppm}$ & 3.534 \\
$\mathrm{P}, \mathrm{ppm}$ & 3701 & $\mathrm{Zn}, \mathrm{ppm}$ & 7.573 \\
$\mathrm{~K}, \mathrm{ppm}$ & 5905 & $\mathrm{Cu}, \mathrm{ppm}$ & 2.199 \\
$\mathrm{Na}, \mathrm{ppm}$ & 1047 & $\mathrm{Fe}, \mathrm{ppm}$ & 34.75 \\
\hline
\end{tabular}

Çizelge 2. Deneme toprağının kimyasal özellikleri.

Table 2. Chemical properties of the experimental soil.

\begin{tabular}{lclc}
\hline Parametreler & Sonuçlar & Parametreler & Sonuçlar \\
\hline Kil, \% & 34.88 & Organik P, ppm & 38.57 \\
Silt, \% & 35.28 & Toplam N, \% & 0.12 \\
Kum, \% & 29.84 & Alınabilir P, ppm & 3.89 \\
Tekstür Sınıfı & Killi Tın & Değişebilir Mg, ppm & 874.3 \\
pH & 7.14 & Değişebilir K, ppm & 81.44 \\
$\mathrm{EC}, \mathrm{dS} \mathrm{m}^{-1}$ & 0.274 & Değişebilir Ca, ppm & 8068 \\
$\mathrm{CaCO}_{3}, \%$ & 26.4 & Alınabilir Zn, ppm & 0.102 \\
$\mathrm{KDK}^{-10}$ & 0.18 & Alınabilir Mn, ppm & 11.71 \\
Organik Madde, \% & 1.25 & Alınabilir Cu, ppm & 3.176 \\
Organik C, \% & 0.68 & Alınabilir Fe, ppm & 8.674 \\
\hline
\end{tabular}


Deneme toprağının killi tın bünyeye sahip olduğu, nötr karakterli, aşırı kireçli ve organik madde açısından orta seviyede olduğu tespit edilmiş, bununla birlikte tuzluluk problemi olmadığı belirlenmiştir. Deneme toprağ 1 FAO (1990)'un sınır değerlerine göre değerlendirildiğinde; toplam N ve alınabilir $\mathrm{P}$ içeriklerinin iyi; değişebilir $\mathrm{Ca}$ ve $\mathrm{Mg}$ içeriklerinin yüksek; değişebilir $\mathrm{K}$ içeriğinin ise az olduğu tespit edilmiştir. Mikro element içerikleri bakımından ise; alınabilir $\mathrm{Fe}, \mathrm{Mn}$ ve $\mathrm{Cu}$ yönünden yeterli, alınabilir $\mathrm{Zn}$ yönünden ise noksanlık gösterebilir durumda olduğu belirlenmiştir. Bitkisel materyal olarak Yedikule marul çeşidi kullanılmıştır.

Denemede bütün marul fidelerini aynı günde dikebilmek için ilk önce 60 . gün daha sonra ise 30 . ve 0 . gün inkübasyona tabi tutulan uygulamalar için vermikompost toprağa karıştırılmış ve marul fideleri aynı gün saksılara dikilmiştir. Yaklaşık olarak 9 hafta yetiştirilmiş olan marul bitkileri kök boğazından kesilerek hasat edilmiştir. Tüm bitkilerin hasadı yapıldıktan sonra kök boğazından kesilen bitki örnekleri laboratuvar ortaminda saf su ile yıkandiktan sonra kese kâğıtlarına konularak ağzı açık olacak şekilde $70^{\circ} \mathrm{C}$ ' de havalandırmalı kurutma dolabında sabit ağırlığa gelinceye kadar kurutulmuştur. Kurumuş olan marul bitkileri öğütüldükten sonra toplam $\mathrm{N}$ modifiye Kjeldahl (Kacar ve İnal 2010) yöntemine göre belirlenirken, $\mathrm{P}, \mathrm{K}, \mathrm{Ca}, \mathrm{S}, \mathrm{B}, \mathrm{Mg}, \mathrm{Fe}, \mathrm{Mn}, \mathrm{Zn}$ ve $\mathrm{Cu}$ içerikleri yaş yakma (Kacar ve İnal 2010) sonucu elde edilen süzükte ICP-OES (Perkin Elmer-Inductively Coupled Plasma) cihazında okunarak belirlenmiştir. Deneme sonuçlarının istatistiksel değerlendirmeleri MINITAB ve MSTAT-C paket programları kullanılarak yapılmış, ortalamalar arası farklılıklar LSD testi ile araştırılmış ve farklı grupların harflendirilmesinde $\% 5$ önemlilik düzeyi esas alınmıştır.

\section{Bulgular ve Tartışma}

Farklı inkübasyon sürelerinde, toprağa uygulanan vermikompostun marul bitkisinin $\mathrm{N}, \mathrm{P}, \mathrm{K}, \mathrm{Ca}, \mathrm{Mg}, \mathrm{S}, \mathrm{Zn}, \mathrm{Fe}$, $\mathrm{Mn}, \mathrm{Cu}$ ile $\mathrm{B}$ içerikleri üzerine etkileri istatistiksel olarak \%0.1 düzeyinde önemli bulunmuş ve elde edilen sonuçlar Çizelge 3 'de verilmiştir.

Çizelge 3'den de görüldüğü üzere, toprağa vermikompost uygulamasında, inkübasyon sürelerinin uzamasına bağlı olarak marul bitkisinin $\mathrm{Mg}$ ve $\mathrm{Ca}$ içerikleri artış göstermiştir. İnkübasyon sürelerinin uzamasına bağlı olarak en yüksek $\mathrm{Mg}$ ve Ca içeriği 60. günde (sırasıly $\% 0.27$ ve $\% 0.79$ ) elde edilmiştir. Ünal ve Katkat (2003), artan miktarlarda toprağa uygulanan arıtma çamurunun mısır bitkisinin $\mathrm{Ca}$ içeriğini kontrolüne göre artırdığını belirlemişlerdir.

İnkübasyon sürelerinin uzamasına bağlı olarak vermikompost uygulamaları marul bitkisinin $\mathrm{N}$ ve Fe içeriklerinin 30. günde artmasına 60. günde azalmasına neden olmuştur. Marul bitkisinin yapraklarında en yüksek $\mathrm{N}$ ve $\mathrm{Fe}$ içeriği 30. günde (sırasıyla \%1.30 ve 31.62 ppm) saptanmıştır (Çizelge 3). Sönmez ve ark. (2011), toprağa vermikompostun $200 \mathrm{~kg} \mathrm{da}^{-1}$ uygulamasının ıspanak bitkisinin Fe içeriğini önemli derecede arttırdığını belirtmişlerdir. Hernandez ve ark. (2010), marul üretiminde $\mathrm{Fe}$ elementinin vermikompost uygulanan yapraklarda daha yüksek oranda olduğunu tespit etmişlerdir. Bitkiler toprağa ilave edilen organik gübrelerden kısa sürede yararlanamazlar. Mineralizasyonun gerçekleşmesi gerekmektedir. Başlangıçta N noksanlığı çeken bitkiler bu sürenin sonunda gelişmelerini hızlandırırlar (Sezen 1984). ElNemr ve ark. (2012), hıyar ekiminden üç hafta sonra 15 gün aralıklarla üç kere uygulanan humik asidin $3 \mathrm{~g} \mathrm{l}^{-1}$ uygulaması ile bitkinin $\mathrm{K}$ ve $\mathrm{Mg}$ içeriğinin arttığını belirlemişlerdir.

Çizelge 3 'den de görüldüğü üzere vermikompost uygulamasında, inkübasyon sürelerinin uzamasına bağlı olarak marul bitkisinin $\mathrm{P}, \mathrm{Zn}$ ve B içeriklerinin azaldığ belirlenmiştir. İnkübasyon sürelerinin uzamasına bağlı olarak en yüksek $\mathrm{P}, \mathrm{Zn}$ ve $B$ içerikleri 0 . günde (sırasıyla $\% 0.10,10.58 \mathrm{ppm}$ ve 7.13 ppm) elde edilmiştir. Çıtak ve ark. (2011), toprakların makro element kapsamı üzerine en iyi sonucu veren ahır gübreli vermikompost uygulamalarının bitki gelişimi üzerine de en iyi sonuçları verdiğini ve vermikompostun, ahır gübresine göre daha yüksek $\mathrm{P}$ içermesine rağmen uygulama miktarları ve mineralizasyon hızlarından kaynaklı olarak ahır gübresinin, bitkinin P kapsamını önemli ölçüde etkilediğini belirtmişlerdir. Hernandez ve ark. (2010), marul üretiminde $\mathrm{Zn}$ içeriğinin vermikompost uygulanan yapraklarda daha yüksek olduğunu tespit etmişlerdir.

İnkübasyon sürelerinin uzamasına bağlı olarak vermikompost uygulamaları marul bitkisinin $\mathrm{K}, \mathrm{Mn}, \mathrm{Cu}$ ve $\mathrm{S}$ içeriklerinin 30. günde azalmasına 60. günde artmasına neden olmuştur. Marul bitkisinin yapraklarında en yüksek $\mathrm{K}, \mathrm{Mn}$ ve $\mathrm{S}$ içeriği 0. günde (sırasıyla \%3.63, 46.45 ppm ve 2058.8 ppm) belirlenirken; $\mathrm{Cu}$ içeriği en yüksek $3.84 \mathrm{ppm}$ ile 60 . günde saptanmıştır. Ceylan ve ark. (2000) domateste yaptıkları çalışmada, sığır gübresinin yaprakların $\mathrm{Cu}$ içeriğini arttırdığını belirlemişlerdir. Pehluvan (2007), çilek bitkilerine hümik asit uygulamalarının yaprakların $\mathrm{Cu}$ içeriğini artırdığını bildirmiştir.

Çizelge 3. Farklı inkübasyon dönemlerinde toprağa uygulanan vermikompostun marul bitkisinin bitki besin element içeriği üzerine etkisi ${ }^{1}$. Table 3. The effect of vermicompost applied to soil in different incubation periods on the plant nutrients contents of lettuce plant ${ }^{1}$.

\begin{tabular}{|c|c|c|c|c|}
\hline Bitki Özzellikleri & 0. Gün & 30. Gün & 60. Gün & Önemlilik Düzeyi \\
\hline Azot $(\%)$ & $1.44 \mathrm{~B}$ & $1.50 \mathrm{~A}$ & $1.34 \mathrm{C}$ & $* * *$ \\
\hline Fosfor $(\%)$ & $0.10 \mathrm{~A}$ & $0.09 \mathrm{~B}$ & $0.07 \mathrm{C}$ & $* * *$ \\
\hline Potasyum (\%) & $3.63 \mathrm{~A}$ & $3.07 \mathrm{~B}$ & $3.58 \mathrm{~A}$ & $* * *$ \\
\hline Kalsiyum (\%) & $0.64 \mathrm{C}$ & $0.69 \mathrm{~B}$ & $0.79 \mathrm{~A}$ & $* * *$ \\
\hline Magnezyum (\%) & $0.22 \mathrm{C}$ & $0.23 \mathrm{~B}$ & $0.27 \mathrm{~A}$ & $* * *$ \\
\hline Kükürt (ppm) & $2058.8 \mathrm{~A}$ & $1511.8 \mathrm{C}$ & $1744.8 \mathrm{~B}$ & $* * *$ \\
\hline Çinko (ppm) & $10.58 \mathrm{~A}$ & $8.50 \mathrm{~B}$ & $7.84 \mathrm{C}$ & $* * *$ \\
\hline Demir (ppm) & $25.063 \mathrm{~B}$ & $31.624 \mathrm{~A}$ & $18.343 \mathrm{C}$ & $* * *$ \\
\hline Mangan (ppm) & $46.45 \mathrm{~A}$ & $33.87 \mathrm{C}$ & $38.05 \mathrm{~B}$ & $* * *$ \\
\hline Bakır (ppm) & $3.57 \mathrm{~B}$ & $3.26 \mathrm{C}$ & $3.84 \mathrm{~A}$ & $* * *$ \\
\hline Bor (ppm) & $7.13 \mathrm{~A}$ & $4.91 \mathrm{~B}$ & $5.17 \mathrm{~B}$ & $* * *$ \\
\hline
\end{tabular}

${ }^{1}$ Değerler 3 tekerrür ortalamasıdır. 
Artan dozlarda vermikompost uygulamalarının marul bitkisinin $\mathrm{N}, \mathrm{P}, \mathrm{K}, \mathrm{Mg}, \mathrm{Cu}, \mathrm{B}$ ve $\mathrm{S}$ içerikleri üzerine etkilerinin istatistiksel olarak \%0.1 düzeyinde; $Z n$ ve Fe içerikleri üzerine $\% 1$; Mn içeriği üzerine $\% 0.5$; Ca içeriği üzerine etkisinin ise istatistiksel olarak önemsiz olduğu belirlenmiş ve sonuçlar Çizelge 4'de verilmiştir.

Çizelge 4'den de görüldüğü üzere artan düzeyde yapılan vermikompost uygulamaları genel olarak marul bitkisinin $\mathrm{N}, \mathrm{P}$ ve $\mathrm{K}$ içeriklerinin artışına neden olmuştur. Vermikompost uygulama dozuna bağlı olarak en yüksek $\mathrm{N}, \mathrm{P}$ ve $\mathrm{K}$ içerikleri $200 \mathrm{~kg} \mathrm{da}^{-1}$ (sirasiyla; \%1.52,\%0.09, \%3.50) dozunda elde edilmiştir. Kütük ve ark. (1999), toprağa uyguladıkları organik materyallerin 1 spanak bitkisinin $\mathrm{K}$ içeriğini arttırdığını belirtmişlerdir. Bizim bulduğumuz $\mathrm{K}$ sonuçlarıyla paralellik göstermektedir. Ceylan ve ark. (2000) ise domateste yaptıkları çalışmada, sığır gübresinin yaprakların $\mathrm{N}$ içeriğini artırdığını bildirmişlerdir.

Artan düzeyde yapılan vermikompost uygulamaları marul bitkisinin $\mathrm{Zn}, \mathrm{Mn}$ ve $\mathrm{Fe}$ içeriklerini arttırmıştır. En yüksek $\mathrm{Zn}$ ve Mn içerikleri $200 \mathrm{~kg} \mathrm{da}^{-1}$ uygulama dozunda (sırasıyla 9.06 ppm ve 39.80 ppm) elde edilirken; en yüksek Fe içeriği 26.10 ppm ile $100 \mathrm{~kg} \mathrm{da}^{-1}$ uygulama dozunda saptanmıştır (Çizelge 4). Çıtak ve ark. (2011), 1spanak bitkisinin en yüksek Fe (342.7 ppm) ve $\mathrm{Zn}$ (38.7 ppm) kapsamlarının kontrol bitkisinde belirlendiğini, uygulamalar içerisinde sırasıyla $\mathrm{VC}_{2}(211.5 \mathrm{ppm}$ $\mathrm{Fe})$ ve $\mathrm{AG}_{1}$ (28.6 ppm Zn) uygulamalarının en yüksek değerleri verdiğini bildirmişler; en düşük bitki gelişiminin olduğu kontrol parselindeki bitkilerde $\mathrm{Fe}$ ve $\mathrm{Zn}$ birikiminin olduğunu düşünmüşlerdir. Bizim elde etmiş olduğumuz sonuçlarımızda da en düşük bitki gelişimi kontrol grubunda, en yüksek $\mathrm{Zn}$ içeriği kontrol uygulamasında belirlenerek Çıtak (2011)'ın yapmış olduğu çalışma ile de paralellik göstermiştir. Hernandez ve ark. (2010); marul üretimini yapılan parsellerin Mn içeriğinin, organik gübreleme yapılan yapraklarda daha yüksek olduğunu tespit etmişlerdir. Marul yapraklarının Mn içerikleri Jones ve ark.(1991) tarafindan yeterli olarak belirlenen 11-250 ppm sinır değerleri ile karşılaştırıldığında; marul yapraklarının Mn içeriklerinin yeterli düzeyde olduğu sonucuna varılmıştır.

Çizelge 4'den de görüldüğü gibi; artan düzeyde yapılan vermikompost uygulamalarının marul bitkisinin $\mathrm{Ca}$ içeriğ üzerine hiçbir etkisi olmamıştır. Artan düzeyde yapılan vermikompost uygulamalarının genel olarak marul bitkisinin $\mathrm{Mg}, \mathrm{Cu}$ ve $\mathrm{B}$ içeriklerinin azalışına neden olduğu belirlenmiştir.
En yüksek $\mathrm{Mg}, \mathrm{Cu}$ ve B içerikleri $0 \mathrm{~kg} \mathrm{da}^{-1}$ (sırasıyla; \%0.25, $4.30 \mathrm{ppm}, 6.10 \mathrm{ppm}$ ) dozunda elde edilmiştir. Demirtaş ve ark. (2014) toprağa farklı dozlarda uygulanan hümik asidin domates bitkisinin $\mathrm{B}$ içeriğinde meydana getirdiği artışın istatistiksel olarak önemli olmadığını, ancak $\mathrm{Cu}$ içeriğinde meydana getirdiği artışın istatistiksel olarak önemli olduğunu belirtmiştir. Peyvast ve ark. (2007) farklı dozlarda yapılan vermikompost uygulamalarının 1spanak bitkisinin mineral madde içeriğini olumlu yönde etkilediğini belirtmişlerdir. Sözüdoğru ve ark. (1996), fasulye bitkisine uygulanan hümik asitlerin $\mathrm{Cu}$ alımına bir etkisinin bulunmadığını belirtmiştir.

Vermikompost uygulama dozu arttıkça, marul bitkisinin S içeriği önce azalıp daha sonra artış göstermiş ve en yüksek $S$

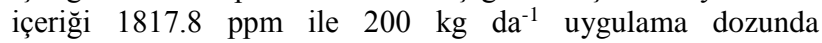
saptanmıştır (Çizelge 4).

\section{Sonuç}

Denemede, farklı inkübasyon dönemlerinde uygulanmış olan vermikompostun yetiştirilen marul bitkisinin bitki besin element içeriği üzerine etkileri farkl11ık göstermiştir.

Araştırma sonucunda; inkübasyon süresinin uzamasına (60. güne doğru) bağlı olarak marul bitkisinin $\mathrm{Mg}$ ve Ca içeriklerinin $\operatorname{arttığı;~Zn,~P~ve~B~içeriklerinin~ise~inkübasyon~sürelerinin~}$ uzamasına bağlı olarak azaldığı tespit edilmiştir.

Marul bitkilerinin $\mathrm{S}, \mathrm{K}, \mathrm{Mn}$ ve $\mathrm{Cu}$ içeriklerinin 30.güne doğru azaldığ ; ancak 60 . günde arttığı; bitkilerin $\mathrm{N}$ ve $\mathrm{Fe}$ içeriklerinin ise 30 . güne kadar arttığı ancak 60 . günde azaldığ 1 belirlenmiştir.

Artan vermikompost uygulama dozlarına bağlı olarak ise marul bitkisinin $\mathrm{N}, \mathrm{P}, \mathrm{K}, \mathrm{Zn}, \mathrm{Mn}$ ve Fe içeriklerinin genel olarak arttığı; $\mathrm{Cu}, \mathrm{Mg}$ ve B içeriklerinin azaldığı belirlenmiştir. Marul bitkisinin Ca içeriği üzerine organik materyal uygulama dozlarının etkisi ise önemsiz bulunmuştur. Artan uygulama dozuna bağlı olarak marul bitkisinin S içeriği önce azalıp daha sonra artış göstermiştir.

Sonuç olarak, vermikompostun toprağa uygulamasının marul bitkisinin bitki besin element içeriği üzerine önemli etkileri olmuştur. Araştırma sonucunda; en iyi sonucun 60 gün inkübasyona bırakılmış ve $200 \mathrm{~kg} \mathrm{da}^{-1}$ vermikompost uygulanmış dozdan elde edildiği belirlenmiştir.

Çizelge 4. Artan dozlarda vermikompost uygulamalarının marul bitkisinin bitki besin element içeriği üzerine etkisi ${ }^{1}$.

Table 4. The effect of increasing doses of vermicompost applications on the plant nutrients contents of lettuce plant ${ }^{1}$.

\begin{tabular}{|c|c|c|c|c|c|}
\hline \multirow[b]{2}{*}{ Bitki Özellikleri } & \multicolumn{4}{|c|}{ Gübre Dozları $\left(\mathrm{kg} \mathrm{da}^{-1}\right)$} & \multirow[b]{2}{*}{ Önemlilik Düzeyi } \\
\hline & $\mathbf{0}$ & 50 & 100 & 200 & \\
\hline Azot $(\%)$ & $1.36 \mathrm{~B}$ & $1.42 \mathrm{~B}$ & $1.42 \mathrm{~B}$ & $1.52 \mathrm{~A}$ & $* * *$ \\
\hline Fosfor $(\%)$ & $0.06 \mathrm{~B}$ & $0.09 \mathrm{~A}$ & $0.09 \mathrm{~A}$ & $0.09 \mathrm{~A}$ & $* * *$ \\
\hline Potasyum (\%) & $3.21 \mathrm{C}$ & $3.42 \mathrm{~B}$ & $3.55 \mathrm{~A}$ & $3.50 \mathrm{~A}$ & $* * *$ \\
\hline Kalsiyum (\%) & 0.70 & 0.73 & 0.70 & 0.69 & öd \\
\hline Magnezyum (\%) & $0.25 \mathrm{~A}$ & $0.23 \mathrm{CB}$ & $0.23 \mathrm{C}$ & $0.24 \mathrm{~B}$ & $* * *$ \\
\hline Kükürt (ppm) & $1843.4 \mathrm{~A}$ & $1704.9 \mathrm{~B}$ & 1721.1 B & $1817.8 \mathrm{~A}$ & $* * *$ \\
\hline Çinko (ppm) & $9.36 \mathrm{~A}$ & $8.99 \mathrm{~A}$ & $8.50 \mathrm{~B}$ & $9.06 \mathrm{~A}$ & $* *$ \\
\hline Demir (ppm) & $24.49 \mathrm{~B}$ & $24.25 \mathrm{~B}$ & $26.10 \mathrm{~A}$ & $25.19 \mathrm{BA}$ & $* *$ \\
\hline Mangan (ppm) & $38.83 \mathrm{~B}$ & $39.44 \mathrm{BA}$ & $39.74 \mathrm{~A}$ & $39.80 \mathrm{~A}$ & $*$ \\
\hline Bakır (ppm) & $4.30 \mathrm{~A}$ & $3.41 \mathrm{~B}$ & $3.29 \mathrm{~B}$ & $3.22 \mathrm{~B}$ & $* * *$ \\
\hline Bor (ppm) & $6.10 \mathrm{~A}$ & $6.54 \mathrm{~A}$ & $6.36 \mathrm{~A}$ & $3.94 \mathrm{~B}$ & $* * *$ \\
\hline
\end{tabular}

${ }^{1}$ Değerler 3 tekerrür ortalamasıdır. 


\section{Kaynaklar}

Ceylan S, Yoldas F, Mordoğan N, Çakıcı H (2000) Domates Yetiştiriciliğinde Farklı Hayvansal Gübrelerin Verim ve Kaliteye Etkisi. III. Sebze Tarımı Sempozyumu, Isparta, s. 51.

Çıtak S, Sönmez S, Koçak F, Yaşin S (2011) Vermikompost ve ahır gübresi uygulamalarının ispanak (Spinacia Oleracea Var. L.) bitkisinin gelişimi ve toprak verimliliği üzerine etkileri. Batı Akdeniz Tarımsal Araştırma Enstitüsü Derim Dergisi 28(1): 56-69.

Demirtaş EI, Öktüren F, Arı N (2014) Domatesin beslenme durumu, verimi ve kalite özelliklerine hümik asitin etkileri. Derim 31(1): 116.

El-Nemr MA, El-Desuki M, El-Bassiony AM, Fawzy ZF (2012) Response of growth and yield of cucumber plants (cucumis sativus 1.) to different foliar applications of humic acid and bio-stimulators. Australian Journal of Basic and Applied Sciences 6(3): 630-637.

FAO (1990) Micronutrient, Assesment at the country level: An International study. FAO Soil Bulletin 63, Rome.

Fritz D (1983) Nitrat in gemuse und grundwasser. vortagstagung bonn universitaets druckerei, Bonn, 1-7.

Garg VK, Gupta R, Yadav A (2010) Vermicomposting technology for solid waste management. http://www.environmentolexpert.com/Files/0/articles/9047/

Vermicomposting_article_for_the_biofertilizer_people.pdf. Erişim 26 Nisan 2015.

Hernandez A, Castillo H, Ojeda D, Arras A, Lopez J, Sanchez E (2010) Effect of vermicompost and compost on lettuce production. Chilean Journal of Agricultural Research 70(4): 583-589.

Jackson MC (1967) Soil Chemical Analysis. Prentice Hall of India Private'Limited, New Delhi.

Jones JB, Wolf B, Mills HA (1991) Plant analysis handbook. MicroMacro Publishing, Athens, Ga., pp. 213.

Kacar B, İnal A (2010) Bitki analizleri. Nobel Akademik Yayınları.

Kacar B (2014) Toprak Analizleri. Nobel Akademik Yayınları (3. Bask1).

Kara EE (1997) Gelemen tarım işletmesindeki toprak serilerinde, inkübasyon süresine bağlı olarak bazı mikrobiyolojik özelliklerinde meydana gelen değişmeler. Tr. J. of Agriculture and Forestry 23 (1999) Ek Sayı 2, 459-466.

Kızıloğlu FT, Bilen S, Ataoğlu N (2001) Farklı topraklara uygulanan azotlu gübrelemenin nitrifikasyon üzerine etkisi. Atatürk Üniv. Ziraat Fak. Degisi 32(2): 137-142.

Kütük C, Topçuoğlu B, Demir K (1999) Toprağa uygulanan farklı organik materyallerin 1spanak bitkisinde verim ile bazı kalite öğeleri ve mineral madde içerikleri üzerine etkileri. Akdeniz Üniversitesi Ziraat Fakültesi Dergisi 12: 31-36.
Lindsay WL, Norvell WA (1978) Development of a DTPA soil test for zinc, 1ron, manganese and copper. Soil Sci. Amer. Jour. 42(3): 421428. Madisson, Wilconsin, USA, pp. 1372-1376.

Ngouajio M, McGiffen ME, Hutchinson CM (2003) Effect of cover crop and management system on weed populations in lettuce. Crop Protection 22: 57-64.

Olsen SR, Dean LA (1965) Phosphorus (Ed. C.A. Black) Methods of Soil Analysis. Part 2. American Society of Agronomy. Inc. Publisher Madison Wisconsin U.S.A. pp. 1035-1049.

Olsen RJ, Hensler RF, Attoe OJ (1970) Effect of manure applicati on, aeration, and soil $\mathrm{pH}$ on soil nitrogen transformations and on certain soil test values. Soil Science Society of America Proceedings 34: 222-225.

Pehluvan, M (2007) Farklı dozlarda sıvı hümik asit uygulamaları ile bakteri (bacillus osu-142) uygulamalarının fern çilek çeşidinde verim, verim unsurları, bitki gelişimi, meyve kalitesi ile bitki besin elementi içerikleri üzerine etkileri. Atatürk Üniversitesi Fen Bilimleri Enstitüsü, Doktora Tezi, Erzurum, s. 129.

Peyvast GH, Olfati JA, Madeni S, Forghani A (2007) Effect of vermicompost on the growth and yield of spinach (Spinacia oleracea L.). J. of Food, Agric. \& Environ. 6(1): 132-135.

Santamaria P (2006) Nitrate in vegetables: toxicity, content, intake and EC regulation. Journal of the Science of Food and Agriculture 86: 1071.

Sezen Y (1984) Gübreler ve gübreleme. Ataturk Univ. Zir. Fak. Topr. Bol. Erzurum.

Sommerfieldt TG, Chang C (1985) Changes in Soil Properties Under Annual Applications of Feedlot Manure and Different Tillage Practices. Soil Sci. Soc. Am. J. 49: 983-987.

Sönmez S, Çıtak S, Koçak F, Yaşin S (2011) vermikompost ve ahır gübresi uygulamalarının ıspanak (Spinacia Oleracea Var. L.) bitkisinin gelişimi toprak verimliliği üzerine etkileri. Batı Akdeniz Tarımsal Araştırma Enstitüsü Derim Dergisi 28(1): 56-69.

Sözüdoğru S, Kütük C, Yalçın R, Usta S (1996) Hümik asidin fasulye bitkisinin gelişimi ve besin maddelerini alımı üzerine etkisi. Ankara Üniversitesi Ziraat Fakültesi Bilimsel Araştırmalar ve İncelemeler, No: 800, Yayın No: 1452. Ankara.

Ünal M, Katkat AV (2003) bisküvi ve şekerleme sanayii arıtma çamurunun toprak özelliklerine ve mısır bitkisinin kimi mineral madde içeriği üzerine etkileri. Uludağ Üniv. Zir. Fak. Derg. 17(1): 107-118.

Venter F (1978) Untersuchungen Uberden Nitrat Gehalt in Gemuse. Der Stickstoff 12: 13-38.

Vural H, Eşiyok D, Duman İ (2000) Kültür Sebzeleri (Sebze Yetiştirme). Ege Üniversitesi Ziraat Fakültesi, Bahçe Bitkileri Bölümü, Bornova, İzmir, s. 440. 